Supporting Information

\title{
Enhanced solubility and antitumor activity of curcumin via breaking and rebuilding of hydrogen bond
}

Qiu-Hong Zhu, Guo-Hao Zhang, Ling He, Song Qin, Jia-He Tian, Lijian Ma, and Guo-Hong Tao*

College of Chemistry, Sichuan University, Chengdu 610064, China.

E-mail: taogh@scu.edu.cn. 
<smiles>COc1cc(/C=C/C(=O)/C=C/c2ccc(/C=C/C(=O)CC(=O)/C=C/c3ccc(O)c(OC)c3)cc2OC)ccc1O</smiles>

Scheme S1. The Synthesis Route of $\mathrm{Na}[\mathrm{Cur}]$ Compound.

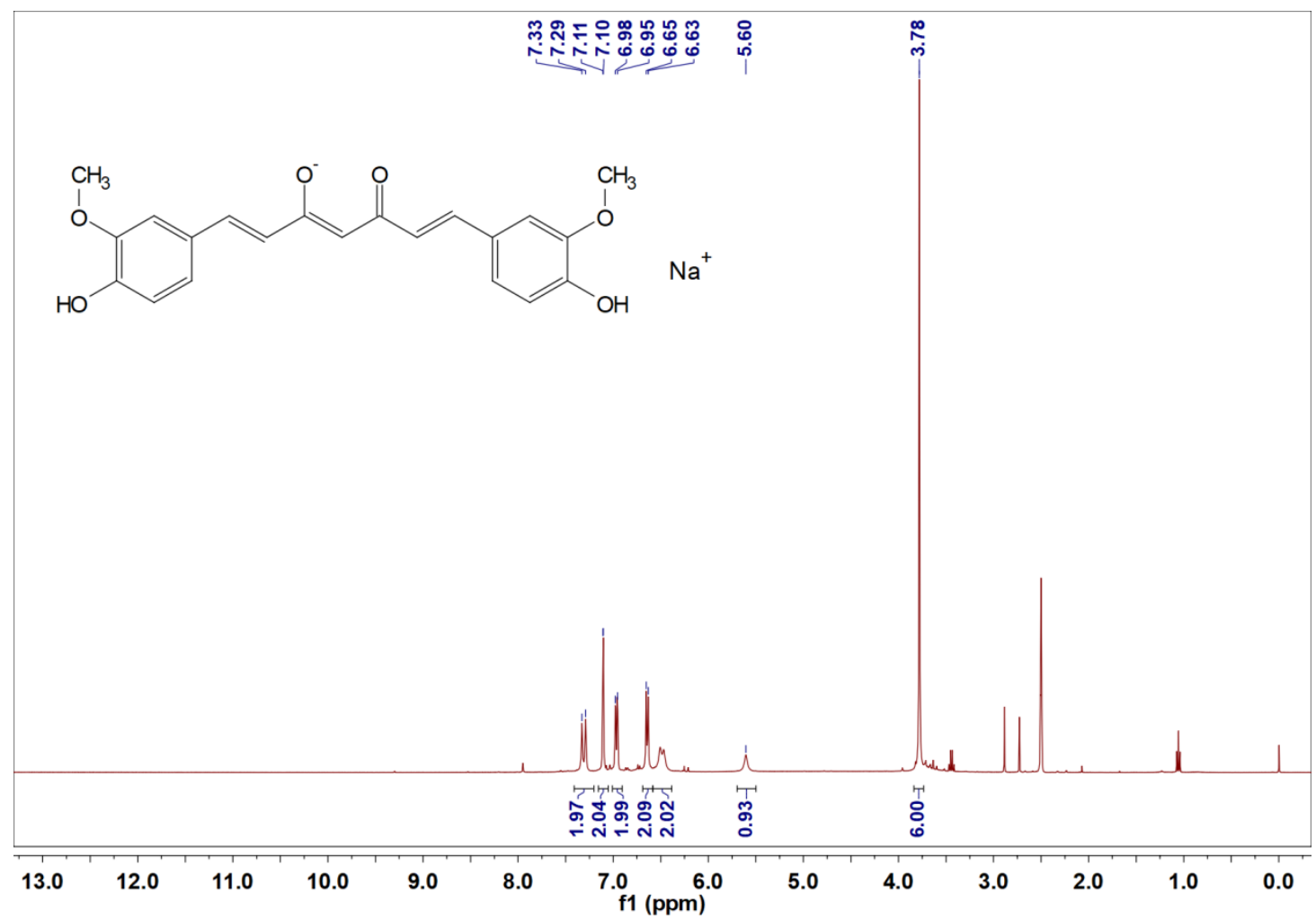

Figure S1. ${ }^{1} \mathrm{H}$ NMR spectrum of compound $\mathrm{Na}[\mathrm{Cur}]$ in DMSO- $d_{6}$.

ESI+

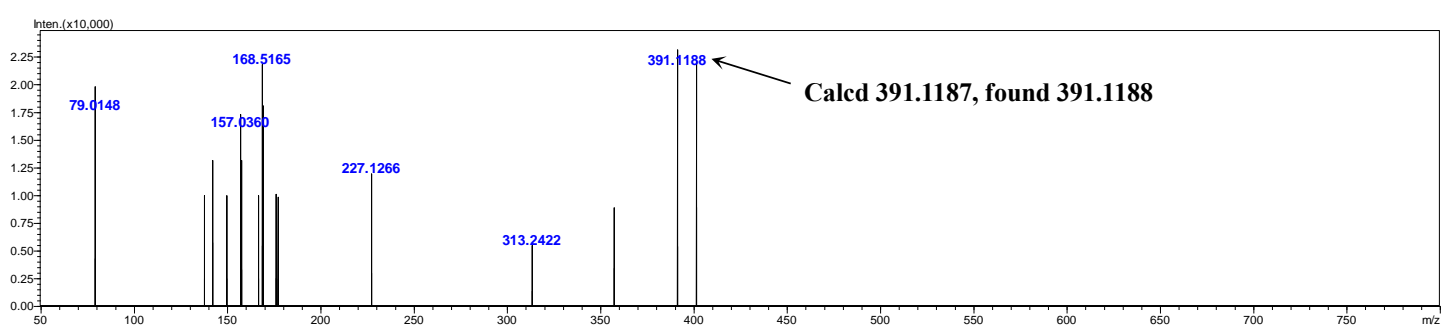

Figure S2. HPLC-MS spectrum of the compound $\mathrm{Na}[\mathrm{Cur}]$. 


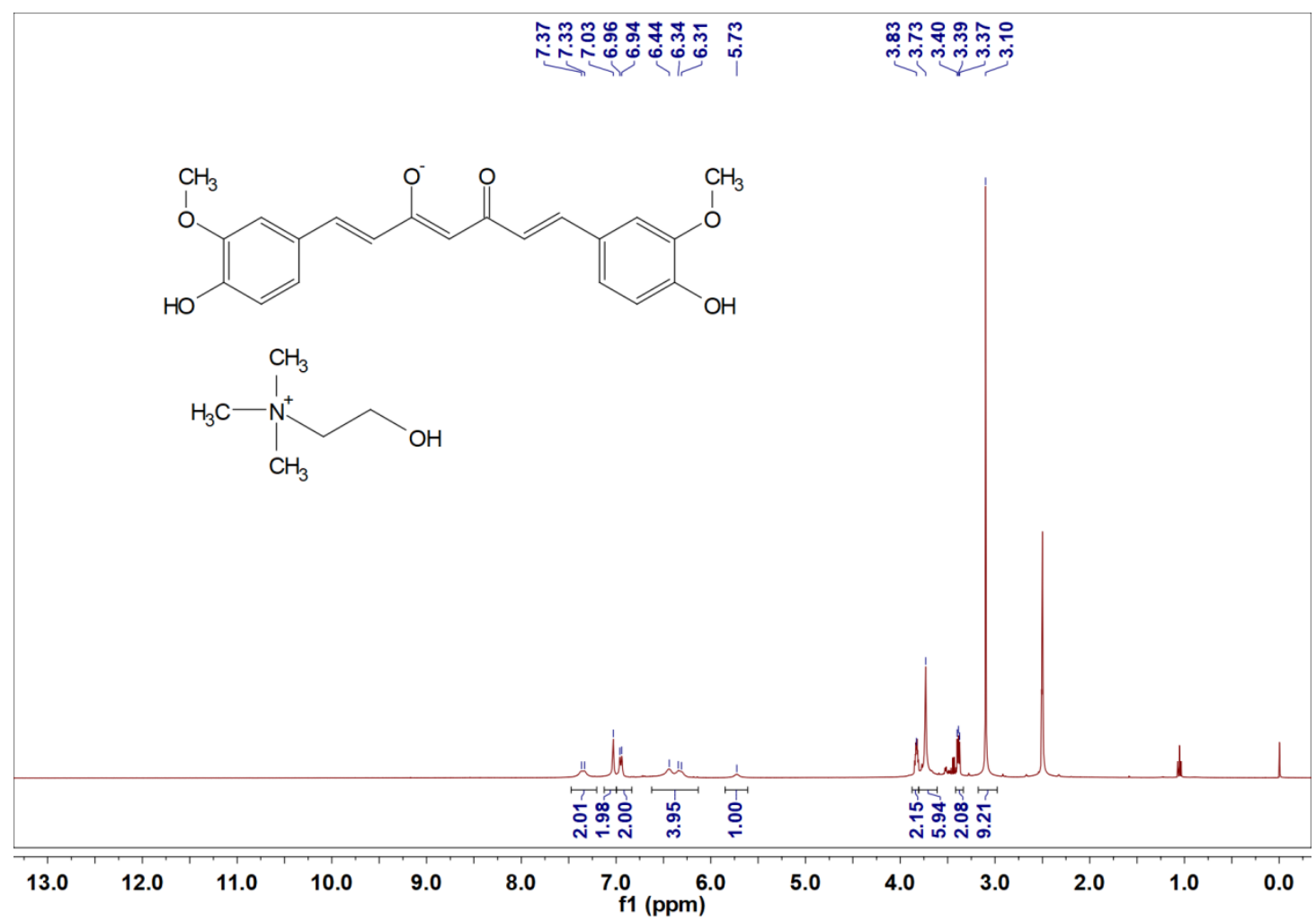

Figure S3. ${ }^{1} \mathrm{H}$ NMR spectrum of compound $[\mathrm{Ch}][\mathrm{Cur}]$ in DMSO- $d_{6}$.

\section{ESI+}

Cholinium cation:

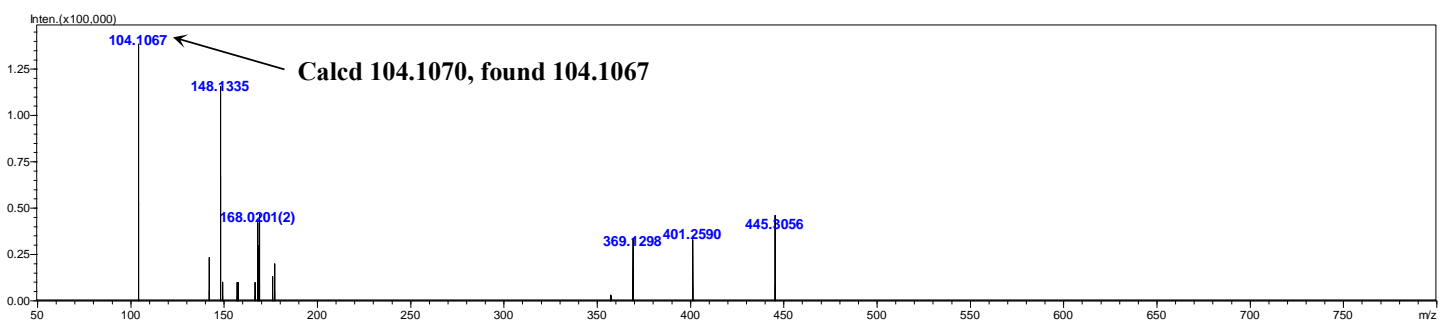

Curcumin anion:

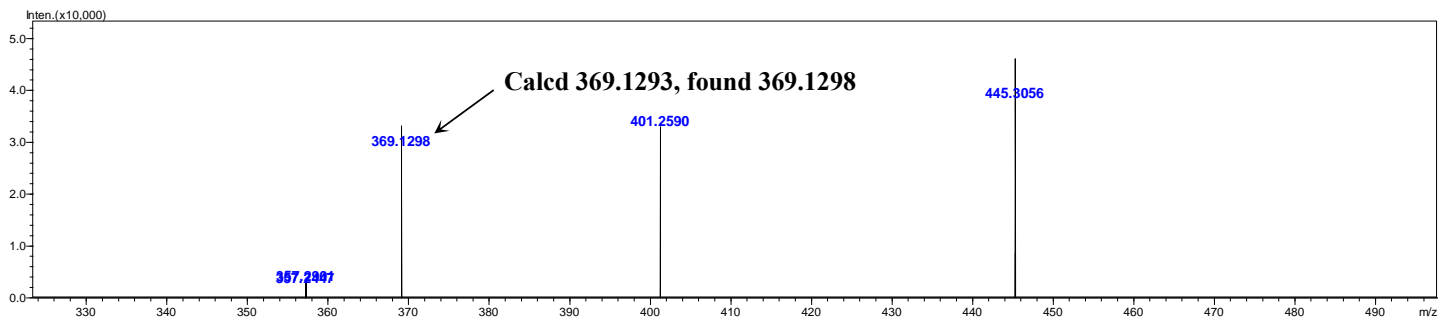

Figure S4. HPLC-MS spectrum of the compound [Ch][Cur]. 


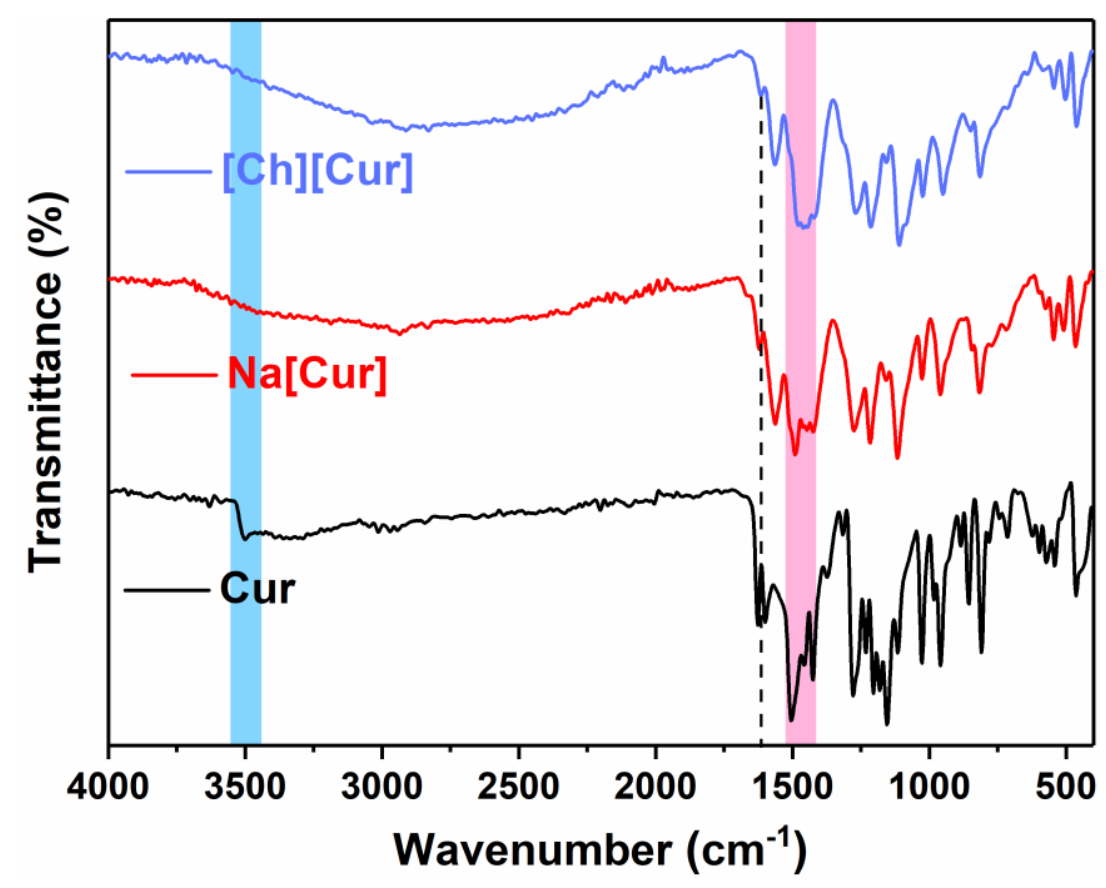

Figure S5. FT-IR spectra of pure $\mathrm{Cur}, \mathrm{Na}[\mathrm{Cur}]$ and $[\mathrm{Ch}][\mathrm{Cur}]$ compounds.

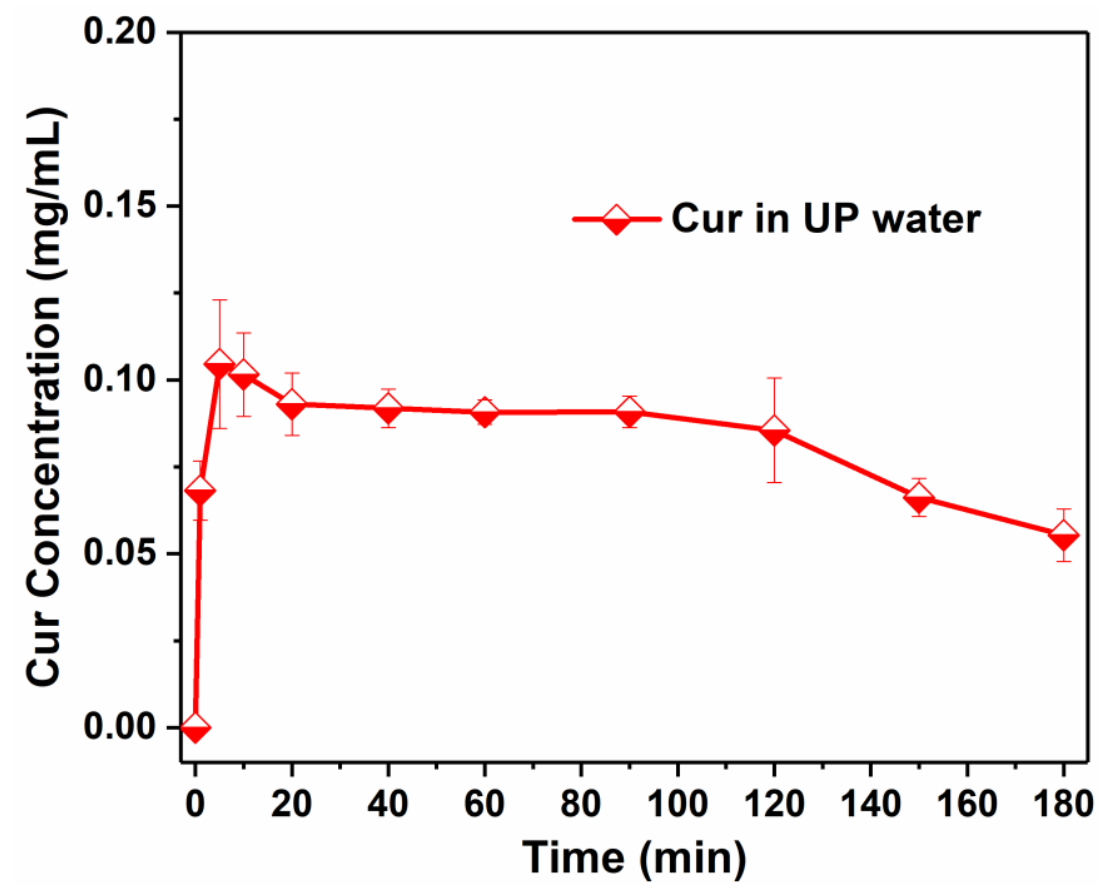

Figure S6. Dissolution profile of pure Cur in UP water. 


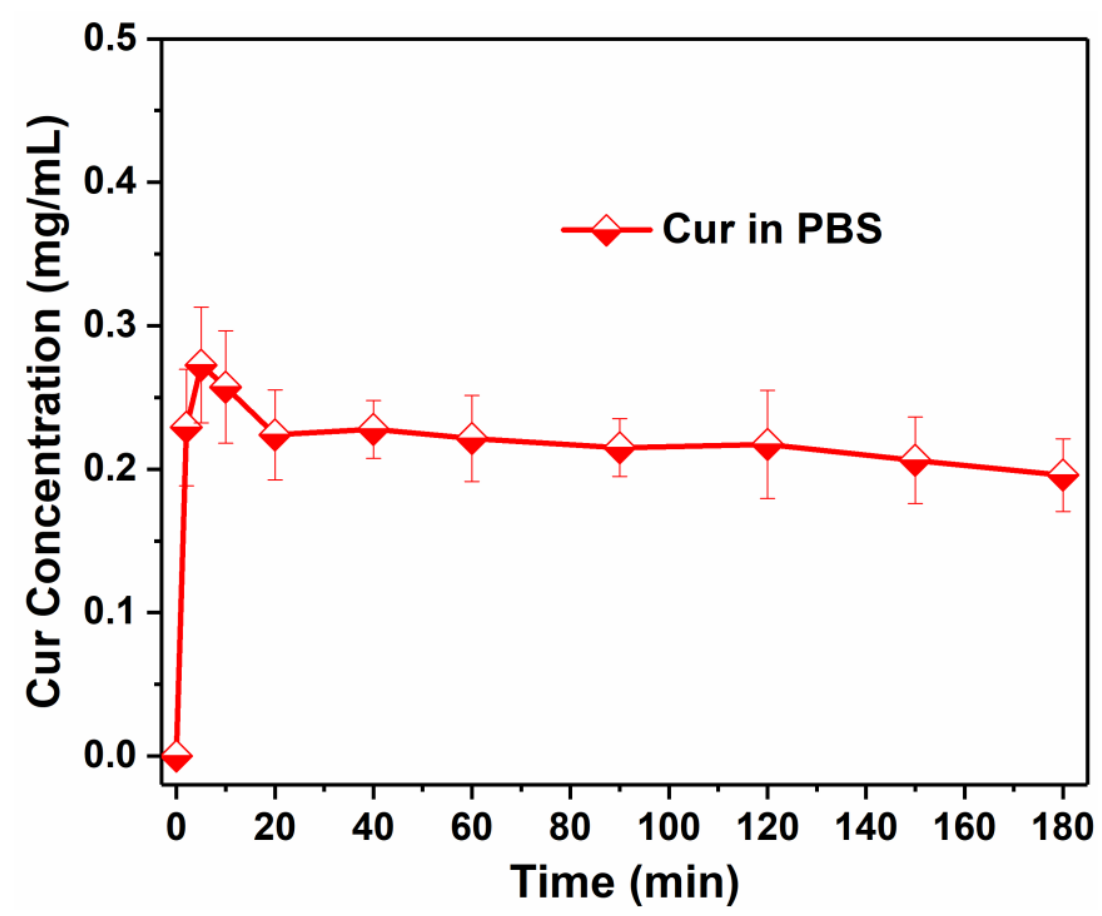

Figure S7. Dissolution profile of pure Cur in PBS media.

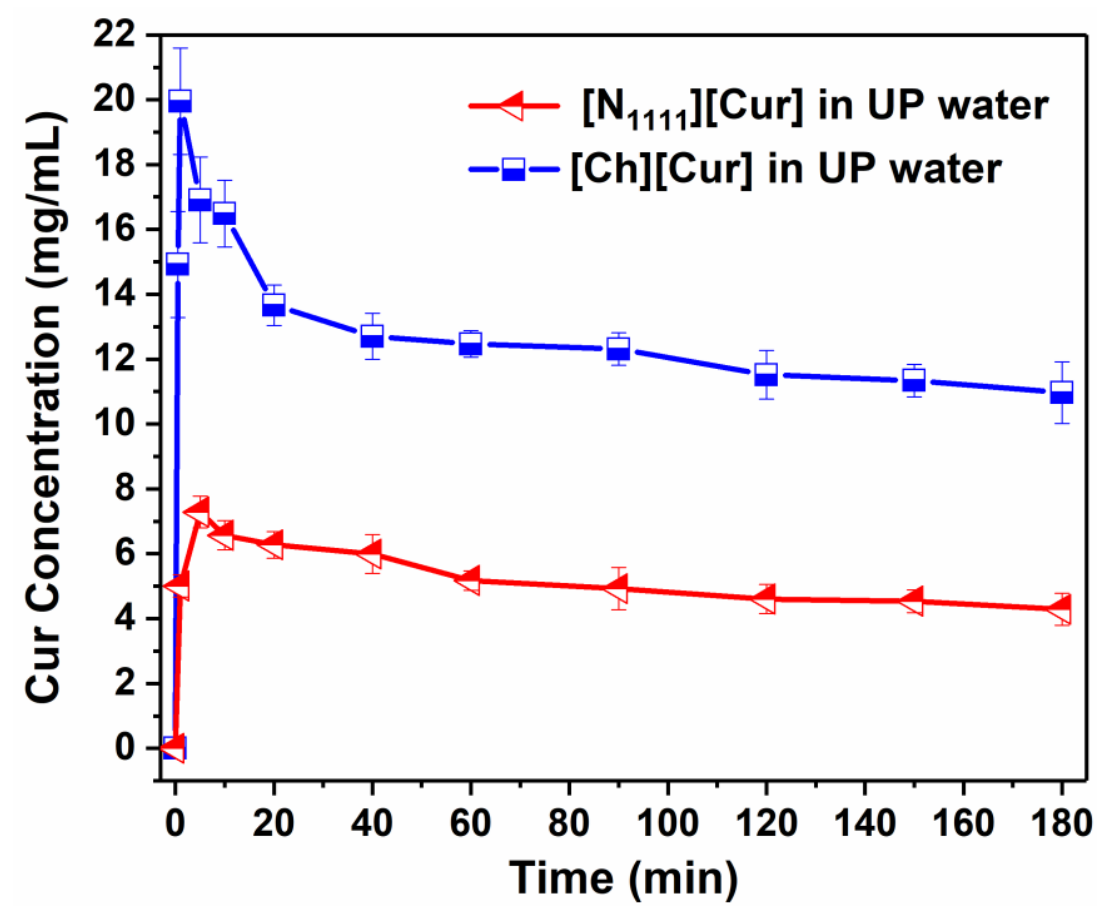

Figure S8. Dissolution profiles of [ $\left.\mathrm{N}_{1111}\right][\mathrm{Cur}]$ compound in UP water. 


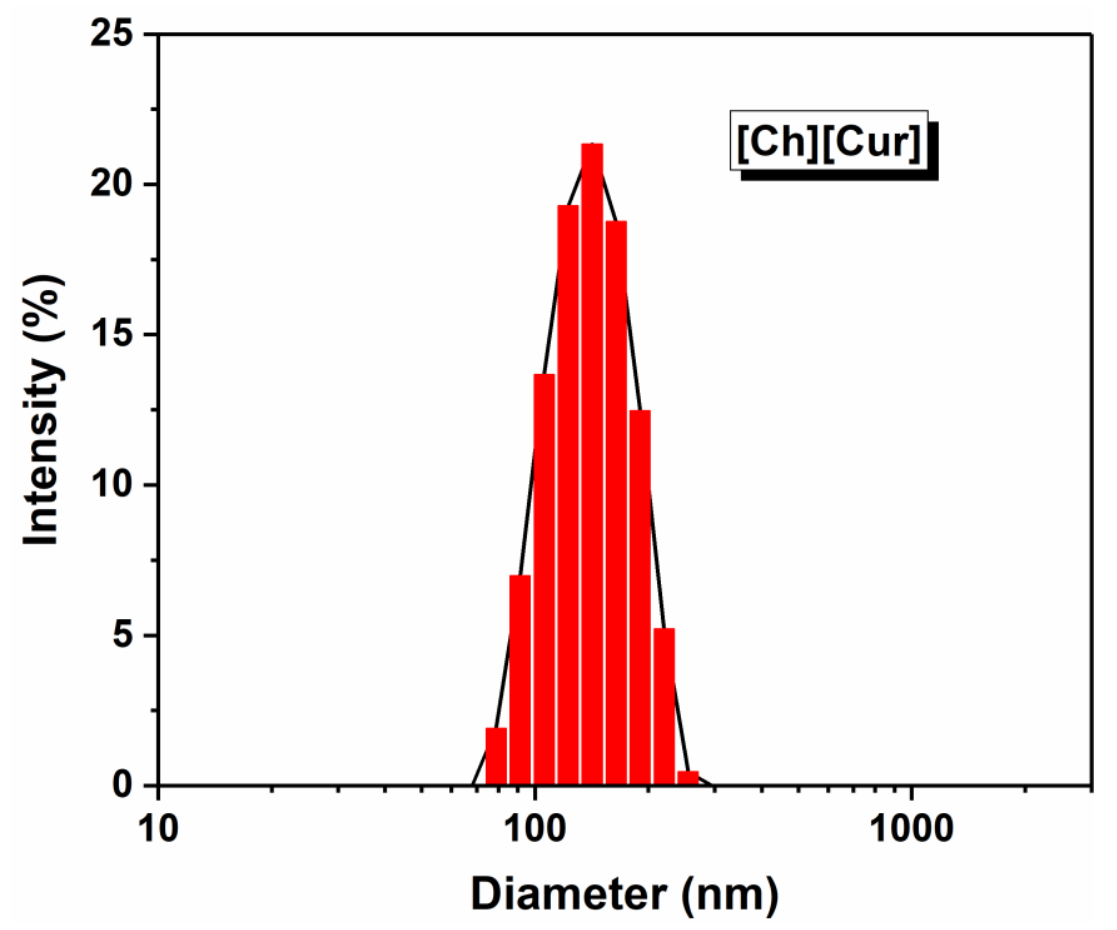

Figure S9. Size distributions of [Ch][Cur] compound in water by DLS analysis.

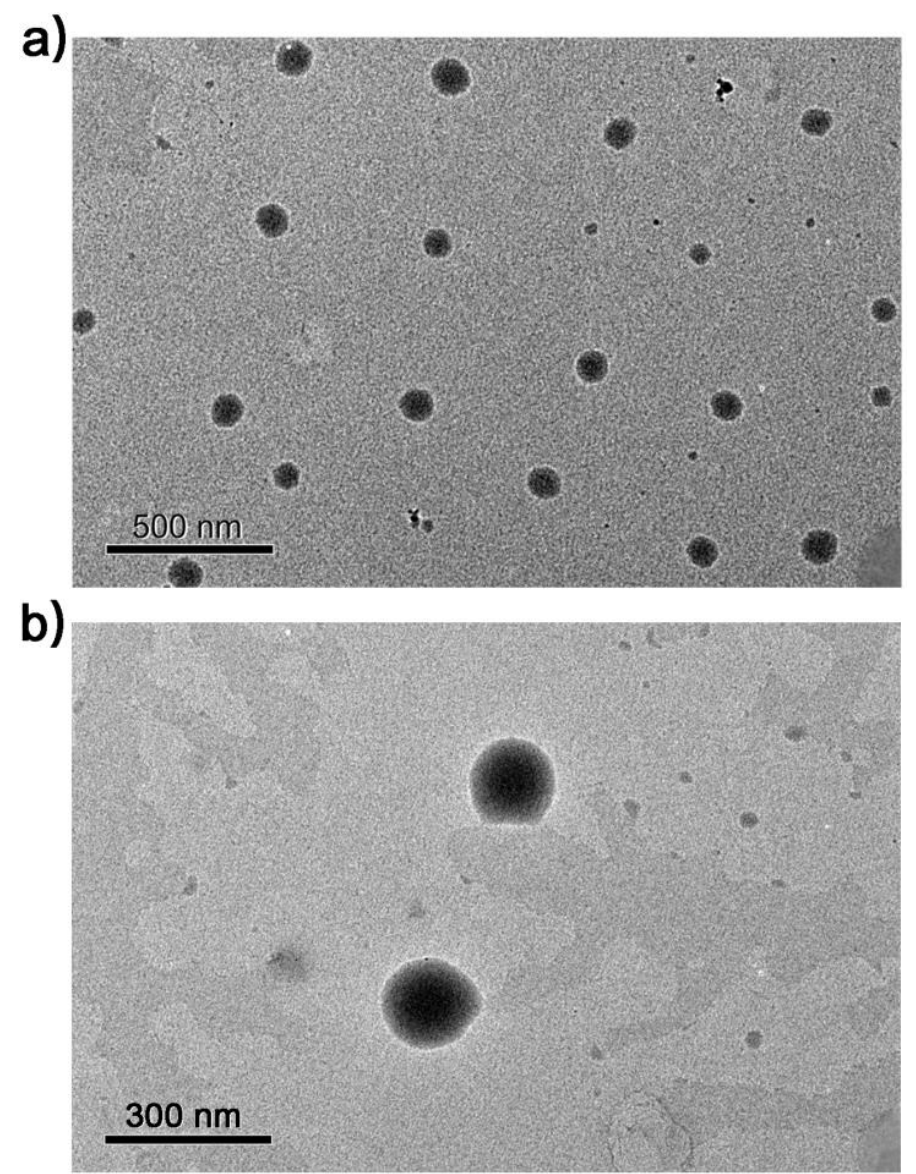

Figure S10. (a) TEM images of the [Ch][Cur] compound and (b) higher magnification. 


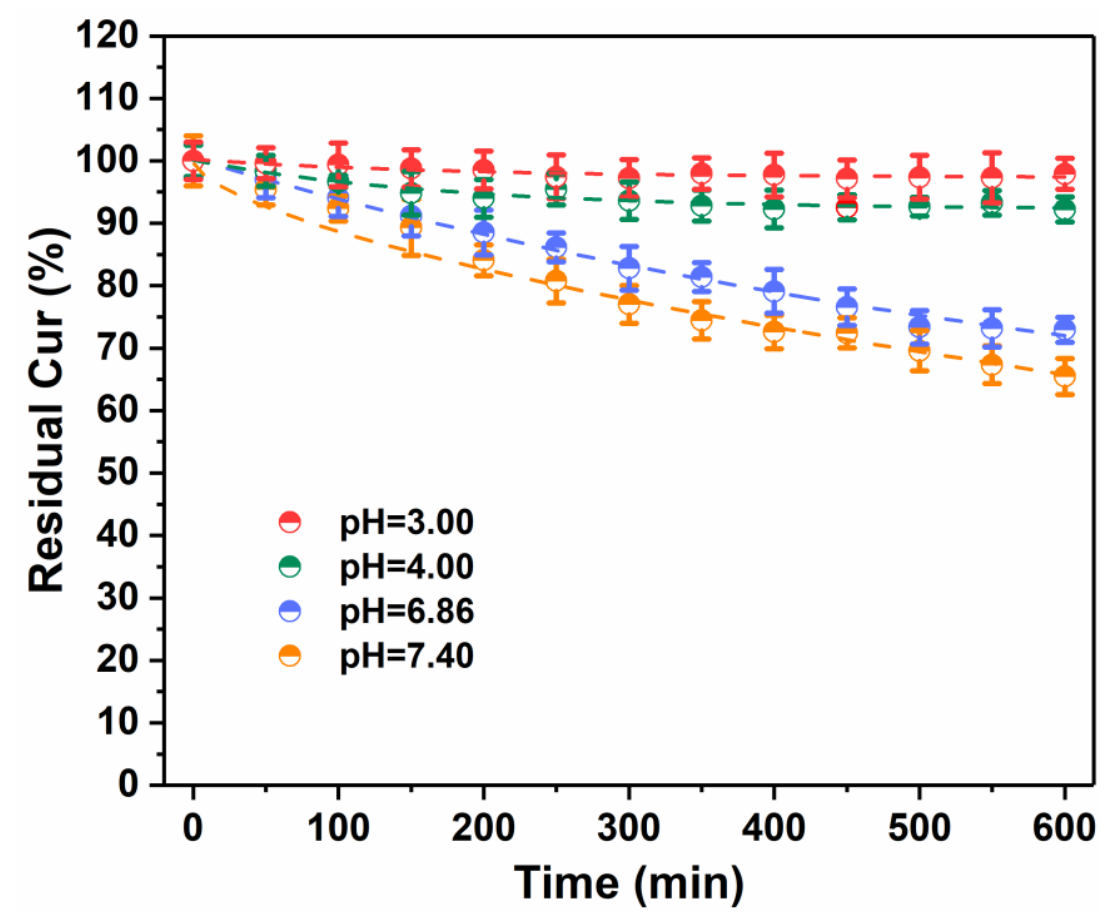

Figure S11. Stability of Cur from the [Ch][Cur] compound in buffers with different $\mathrm{pH}$ values.

a)
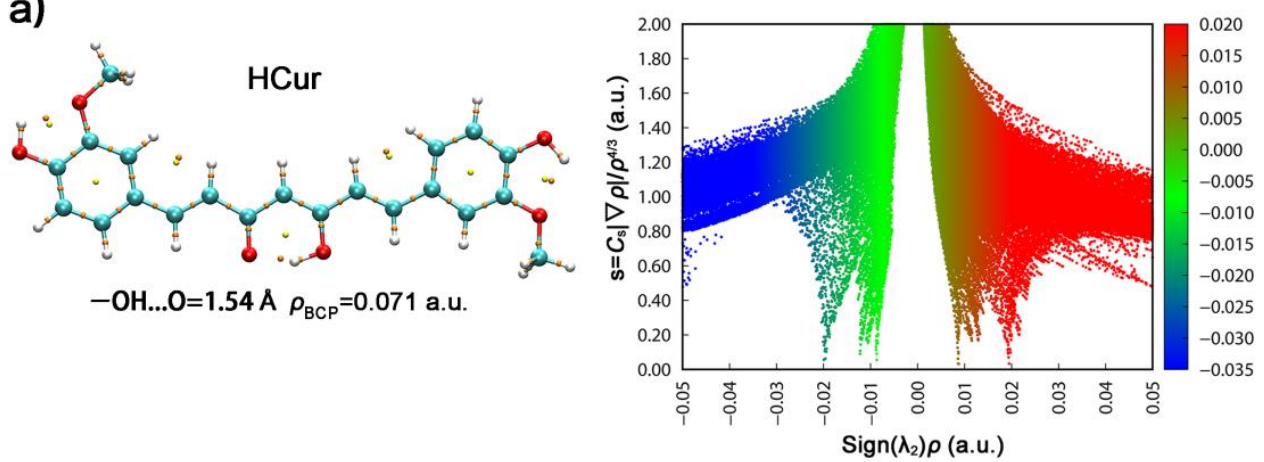

b)

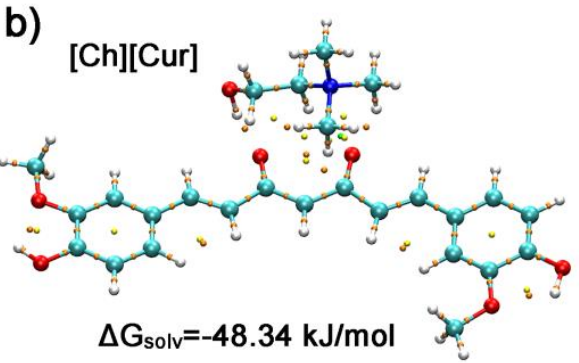

$-\mathrm{OH} . . .0=1.68 \AA \rho_{\mathrm{BCP}}=0.046$ a.u.

$-\mathrm{CH} . . . \mathrm{O}=2.28 \AA \rho_{\mathrm{BCP}}=0.015$ a.u

$-\mathrm{CH} . . .0=2.29 \AA \rho_{\mathrm{BCP}}=0.014$ a.u.

$-\mathrm{CH} . . . \mathrm{O}=2.51 \AA \rho_{\mathrm{BCP}}=0.0098$ a.u

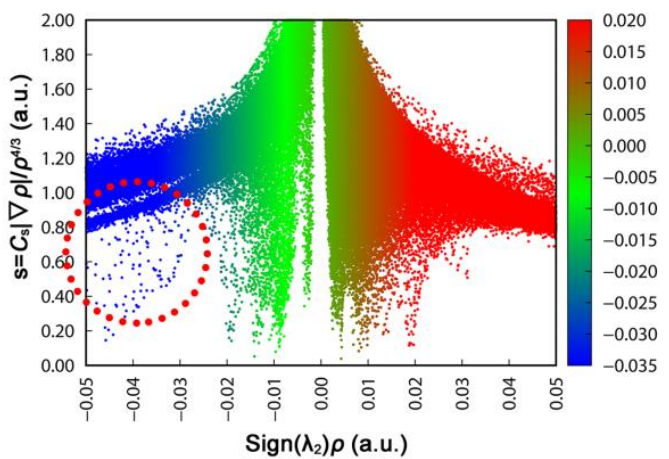

Figure S12. QTAIM analysis and RDG color-filled maps for (a) Cur and (b) [Ch][Cur] compounds at the B3LYP(PCM-D3, water)/6-31++G(d,p) level. 
a)
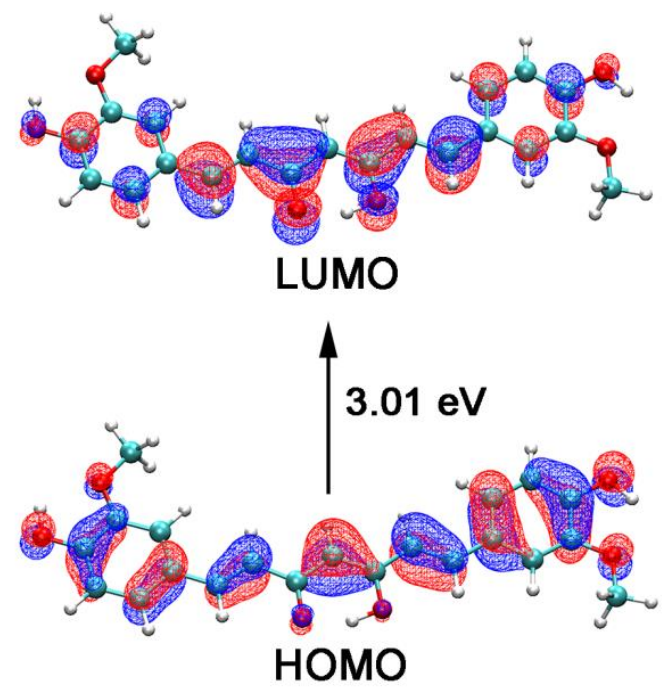

Cur

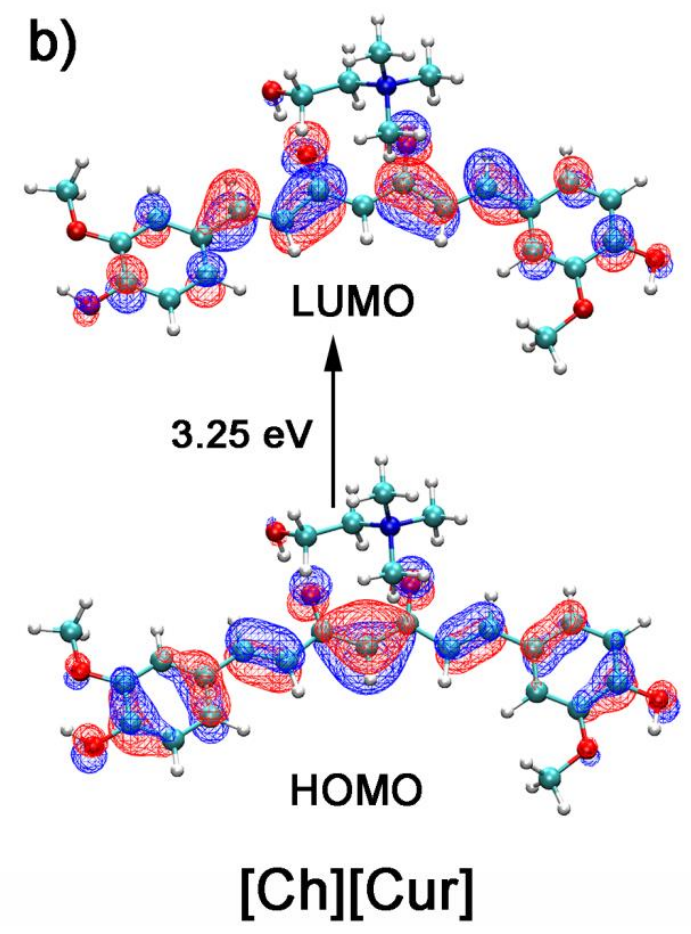

[Ch][Cur]

Figure S13. HOMO-LUMO surfaces for (a) Cur and (b) [Ch][Cur] compounds at the B3LYP(PCM-D3, water)/6-31++G(d,p) level.

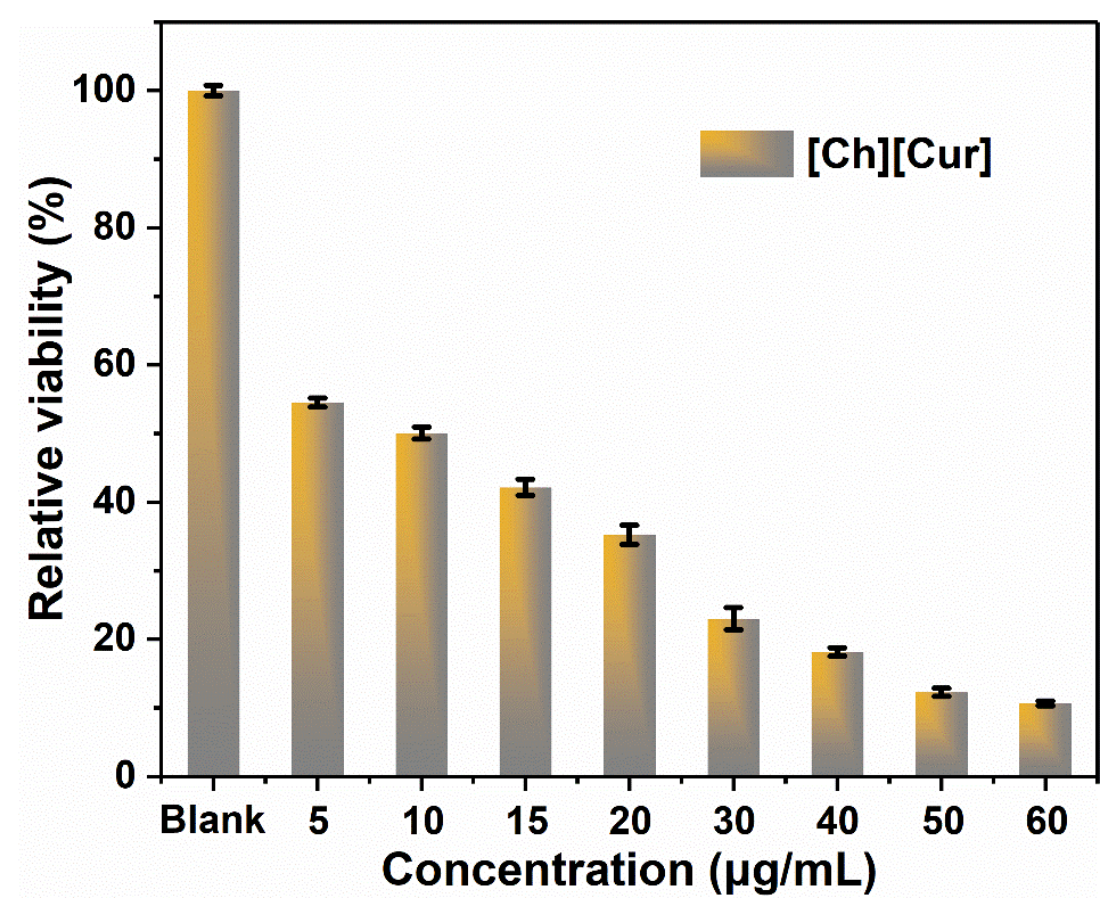

Figure S14. Cell viability of $[\mathrm{Ch}][\mathrm{Cur}]$ compound at different concentration. The viability of HepG2 cells undergo decrease as the enhanced amount of [Ch][Cur] drug. 


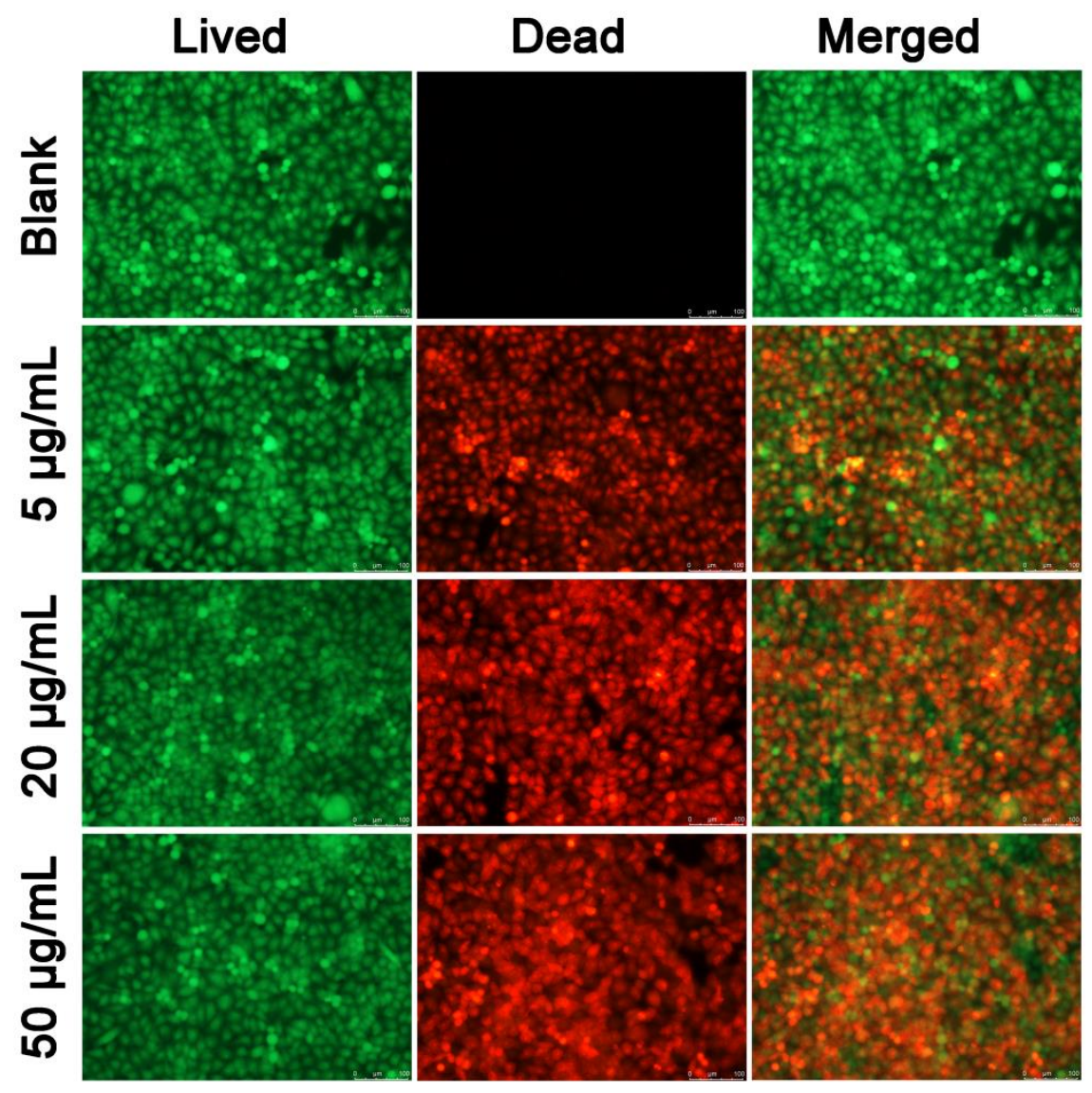

Figure S15. Fluorescent images for Calcein-AM/PI staining of HepG2 cells incubated with the different concentrations of [Ch][Cur] compound.

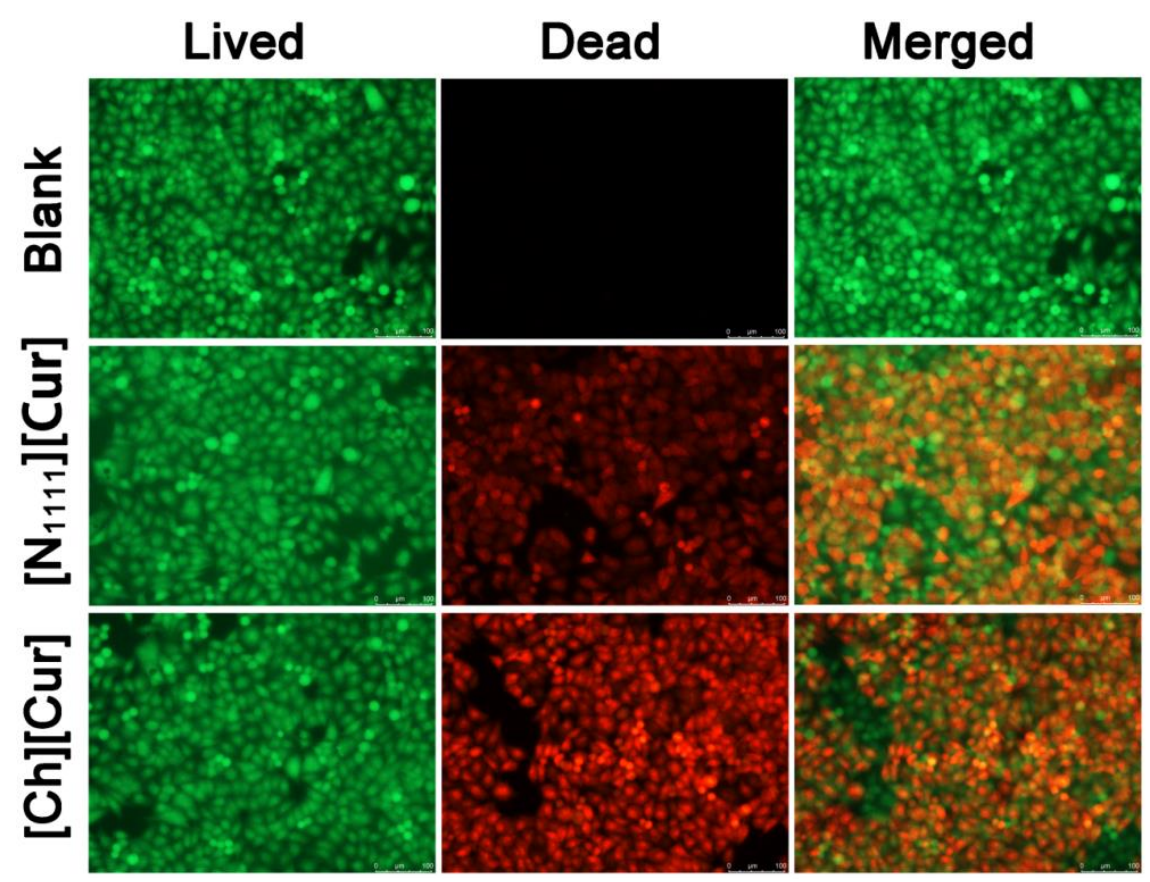

Figure S16. Fluorescent images for Calcein-AM/PI staining of HepG2 cells incubated with $\left[\mathrm{N}_{1111}\right][\mathrm{Cur}]$ and $[\mathrm{Ch}][\mathrm{Cur}]$ compounds of $50 \mu \mathrm{g} \mathrm{m}^{-1}$. 


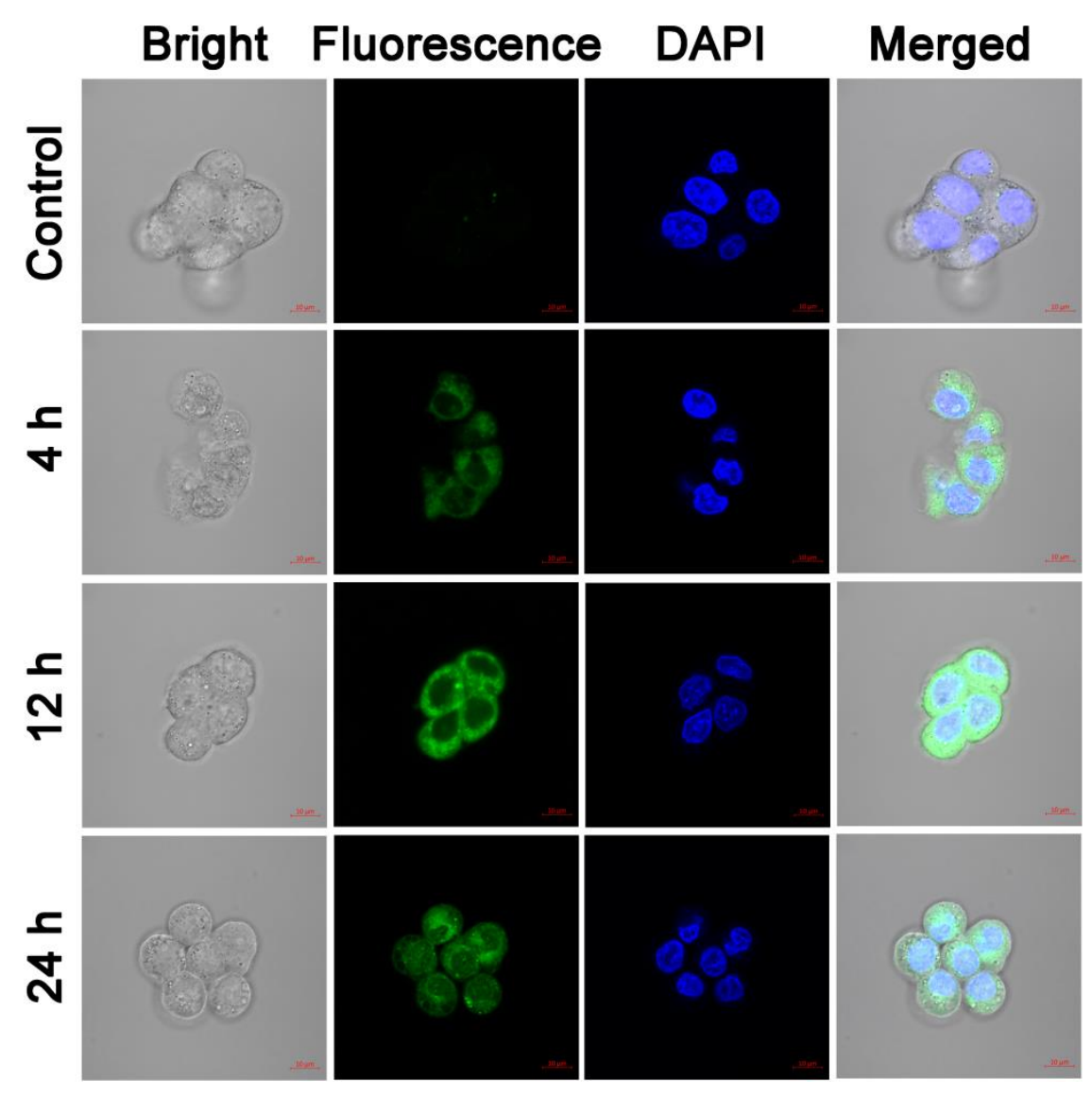

Figure S17. Time-dependent CLSM images for HepG2 cells incubated with [Ch][Cur] compound of $10 \mu \mathrm{g} \mathrm{mL} \mathrm{m}^{-1}$.

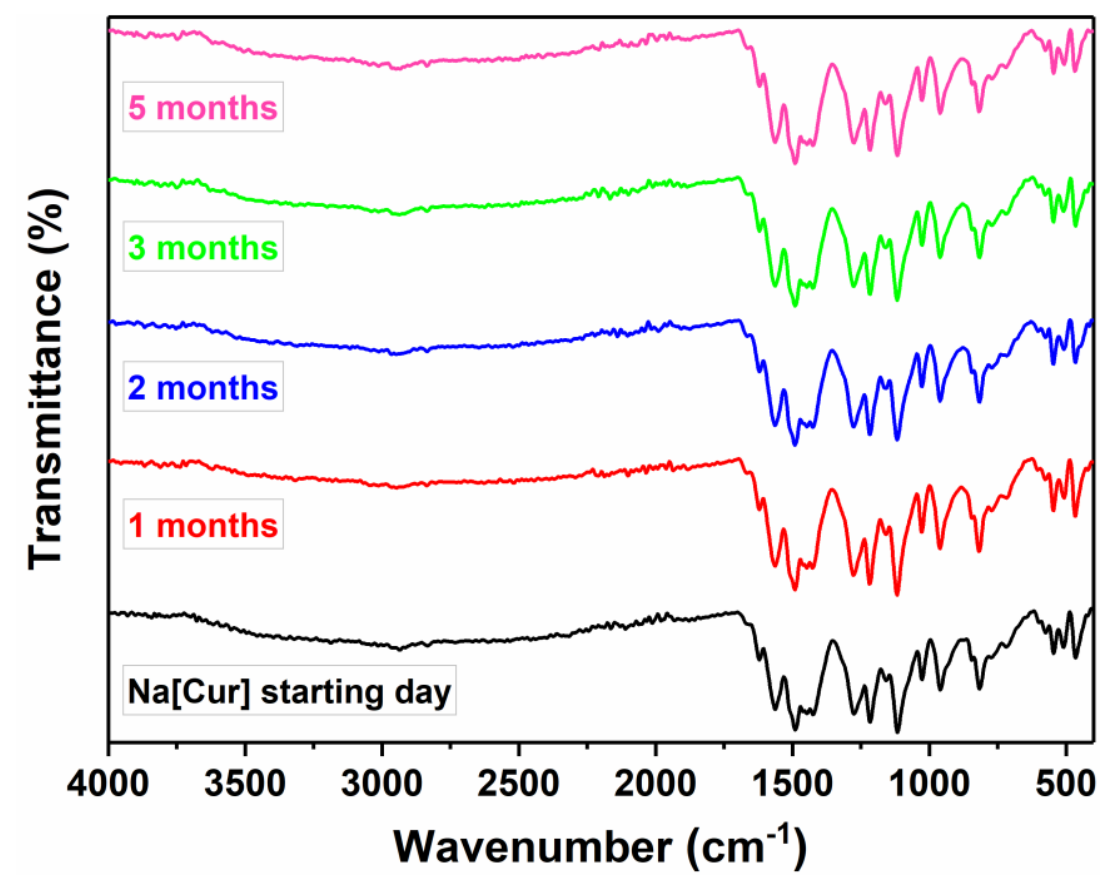

Figure S18. FT-IR spectra of $\mathrm{Na}[\mathrm{Cur}]$ compound at different time points at room temperature. 


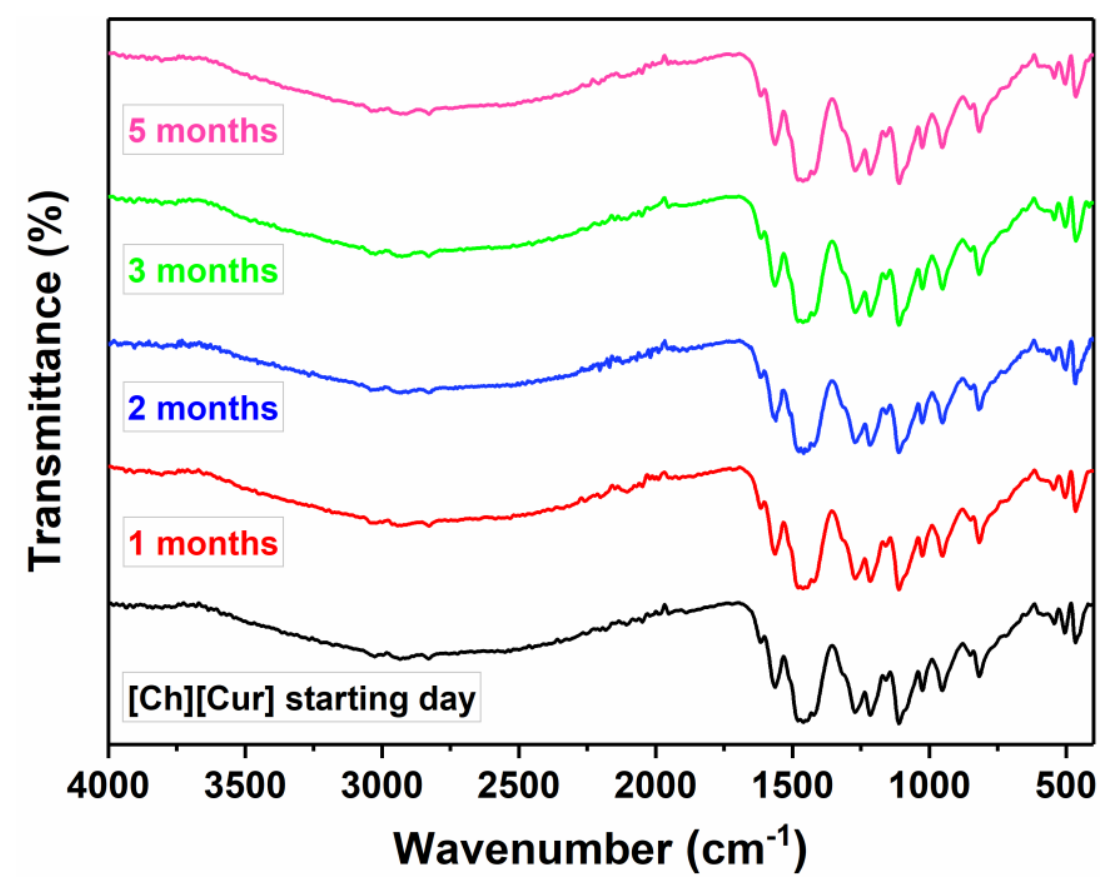

Figure S19. FT-IR spectra of [Ch][Cur] compound at different time points at room temperature..

Table S1. Water, $\mathrm{CH}_{2} \mathrm{I}_{2}$ contact angle and surface energy of compounds $\mathrm{Cur}, \mathrm{Na}[\mathrm{Cur}]$, and [Ch][Cur].

\begin{tabular}{crrccc}
\hline Compound & $\begin{array}{c}\text { Water } \\
\text { contact } \\
\text { angle }\left(^{\circ}\right)\end{array}$ & $\begin{array}{c}\mathrm{CH}_{2} \mathrm{I}_{2} \\
\text { contact } \\
\text { angle }\left(^{\circ}\right)\end{array}$ & $\begin{array}{c}\text { Polar } \\
\text { surface energy } \\
\gamma^{\mathrm{p}}\left(\mathrm{mN} \mathrm{m}^{-1}\right)\end{array}$ & $\begin{array}{c}\text { Dispersive } \\
\text { surface energy } \\
\gamma^{\mathrm{d}}\left(\mathrm{mN} \mathrm{m}^{-1}\right)\end{array}$ & $\begin{array}{c}\text { Total surface } \\
\text { free energy } \\
\gamma^{\text {tot }}\left(\mathrm{mN} \mathrm{m}^{-1}\right)\end{array}$ \\
\hline $\mathbf{C u r}$ & 66.34 & 20.16 & 41.36 & 8.63 & 49.99 \\
$\mathbf{N a}[\mathbf{C u r}]$ & 41.45 & 19.93 & 35.84 & 25.03 & 60.87 \\
{$[\mathbf{C h}][\mathbf{C u r}]$} & 34.56 & 19.83 & 34.73 & 29.61 & 64.34 \\
\hline
\end{tabular}

